\title{
Analysis of white pepper essential oil components using gas chromatography-mass spectroscopy
}

\author{
Purwaniati, Gilang Eka Permana, Indro Pamudjo \\ Pharmacy analysis and medicinal chemistry, Pharmacy Faculty, Universitas Bhakti Kencana
}

Keywords
Essential oils
GC-MS
White pepper
Correspondence
Purwaniati
Pharmacy analysis and medicinal chemistry
Pharmacy Faculty
Universitas Bhakti Kencana
Soekarno-Hatta 754
Bandung 40615
Indonesia
purwaniati@bku.ac.id

\section{Introduction}

Pepper crops form some of the most widely cultivated plantations in Indonesia. According to the 2017 statistics on the county's plantation commodities, this spice was also widely grown on the Java, Sumatra, Kalimantan, and Sulawesi Islands. Pepper plants produce black and white fruits, which can only be distinguished as a result of differences in post-harvest handling procedures (Zhao et al., 2005). White pepper can be used as a cooking spice, flavouring, meat preservative and traditional medicinal ingredient (Direktorat Jendral Perkebunan, 2019).

Essential oils are a mixture of low molecular weight molecules that are responsible for producing distinct aromas. The quality, freshness and uniqueness of the oils make them very valuable (Calo et al., 2015). Nonetheless, heat, humidity and oxygen greatly affect their stability, thus decreasing their quality. Essential oils are volatile and can be produced from the roots, leaves, stems, fruits, and seeds of various plants. They can also be obtained through distilling water vapour and from some animals, such as musk, sperm whales, and even microorganisms (Li et al., 2019).

The use of essential oils in the industry is quite extensive. In the food industry, they are widely used as flavouring ingredients or flavour enhancers (Calo et al., 2015; Z. Liu et al., 2019). Meanwhile, in the pharmaceutical industry, they are widely used as antibacterial agents ( Calo et al., 2015; Tamokou et al., 2017). These oils dissolve in fat underneath the skin because they are biodegradable and can be absorbed into blood vessels. In research carried out by $\mathrm{Hu}$ and the authors (2019) and Demirok Soncu and the authors (2018), it was shown that they act as very effective antifungal agents.

In the cosmetics industry, essential oils such as Patchouli oil, fragrant root and sandalwood are widely used as perfumes, while those made from pepper, ginger, cinnamon, cloves and coriander are widely used as cooking spices (Calo et al., 2015).

Essential oils are insoluble in water but are soluble in alcohol, ether, and fixed oils. Generally, they are 
colourless and liquid at room temperature. The composition of these oils is very dependent on the species of plant that they were extracted from, their growth location, the time of harvest, and the extraction techniques used. Based on their chemical structure, the compounds within these oils can be classified as terpenes, straight-chain compounds without side chains, phenylpropanoids (benzene derivatives), and more (Moghaddam \& Mehdizadeh, 2017).

Various factors can qualitatively and quantitatively affect the chemical composition of essential oils. One of which is the environment, as it can greatly affect the metabolic pathways of plants, which in turn leads to variations within their chemical components. In addition, plant age, rainfall, luminosity, soil composition, environmental pollution and microorganisms in the soil greatly affect the chemical components produced by plants (Fokom et al., 2019).

Essential oil analysis is generally carried out using gas chromatography (GC) or gas chromatography-mass spectroscopy (GC-MS) methods. GC is a chromatographic method that uses gas as a mobile phase (L. Liu et al., 2007).

\section{Method}

This study was carried out using experimental methods, starting with sample preparation, distilling the essential oils, determining the optimum conditions needed for GC-MS, and analysing the oils using GC-MS at optimum conditions.

\section{Materials and tools}

Materials: toluene, aqua, n-hexane and white pepper seeds samples from the Java, Kalimantan, Sumatera, and Sulawesi Islands. Tools: GC-MS Agilent Technologies 7890A, a steam distillation apparatus, and glassware.

\section{Sample preparation}

Raw white peppers were obtained from the Java, Kalimantan, Sumatera and Sulawesi Islands. These were purchased directly from the farmers on these islands. In order to further ensure the authenticity of the materials, a determination process was carried out in the Institute Technology of Bandung (ITB) Bioengineering Science School laboratory.

\section{Essential oil distillation}

The steam distillation method was used to distil these oils. This method resembled the boiling method; however, in this case, the water did not come into direct contact with the distilled materials.

\section{Essential oils analysis with GC-MS}

After determining the conditions needed for the GC-MS analysis, the essential oils were then analysed under the optimum conditions.

\section{Result and discussion \\ Sample preparation}

Based on the plant determination results, the sample proved to be white pepper.

The plant's taxonomy was as follows:

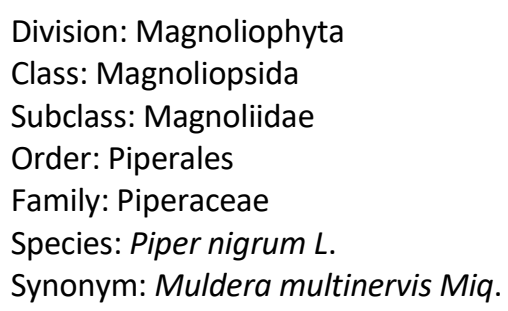

\section{Distillation of the essential oils}

The distillation process for the essential oils lasted 6 hours and was declared complete when the produced condensate no longer contained oil.

\section{Analysis of essential oil components}

The optimum conditions needed for the GC-MS oil analysis can be seen in Table I. Analysis of the essential oils using the GC-MS showed that the essential oils made from white peppers from the Java, Kalimantan, Sumatra and Sulawesi Islands contained almost the same components. Moreover, it showed that there were 22 component compounds within the oils. The essential oil components can be seen in Table II. White pepper chromatogram samples from the Java, Kalimantan, Sumatra and Sulawesi Islands can be seen in Figure 1.

Of the 22 compounds identified, the 6 with the largest compositions differentiated the essential oils based on which region they originated from. These six compounds were alpha-pinene, beta-pinene, delta-3-carene, sabinene, dl-limonene, and caryophillene. The white pepper from Java Island was more dominant in betapinene, dl-limonene, and delta-3-carene compared to those from the other islands. Sabinene was most commonly found in the essential oils from Sumatra Island, alpha-pinene was most commonly found in the essentials oils from Kalimantan Island, and caryophyllene was most commonly found in the essentials oils from on Sulawesi Island. This study showed that the differences in cultivation location affected the relative composition of the essential oils. 
Table I: The optimum GC-MS conditions

\begin{tabular}{ll}
\hline Condition & Description \\
\hline Gas chromatography & Agilent Technologies 7890A \\
The brand & HP-5MS, length 30m, diameter \\
Coulomb & $0.25 \mathrm{~mm}$ \\
Carrier gas & Helium \\
Detector & Mass spectroscopy \\
Injection volume & $1 \mathrm{~mL}$ \\
Injection technique & $\mathrm{Split}$ \\
Split ratio & $25: 1$ \\
Temperature programme: & \\
Injector temperature & $250^{\circ} \mathrm{C}$ \\
Initial temperature & $40^{\circ} \mathrm{C}$ \\
Temperature rate & $10^{\circ} \mathrm{C} /$ minute \\
Final temperature & $40^{\circ} \mathrm{C}$ \\
Intercept temperature & $280^{\circ} \mathrm{C}$ \\
Detector temperature & $250^{\circ} \mathrm{C}$ \\
Mass spectroscopy: & \\
Merck & Agilent Technologies $5975 \mathrm{C}$ \\
Mass range & \\
Resolution & 1188 \\
\hline & \\
\hline
\end{tabular}

a) Kalimantan island

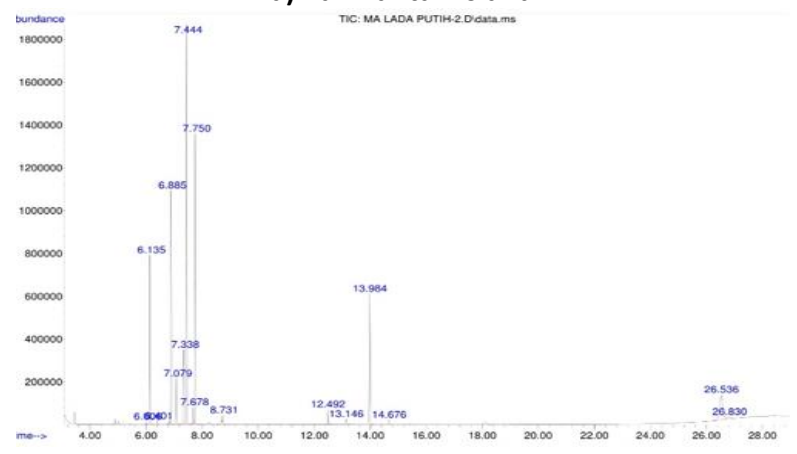

c) Sulawesi island

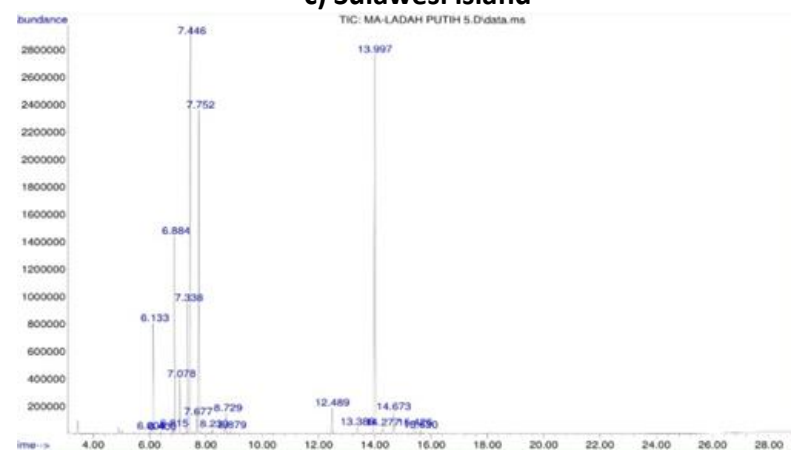

Table II: Essential oil components present

\begin{tabular}{ll}
\hline $\begin{array}{l}\text { Retention } \\
\text { time } \\
\text { (minutes) }\end{array}$ & Compound names \\
\hline 6.006 & 1-isopropyl-4-metthylbicyclo[3.1.0]hex-2-ene \\
6.130 & Alfa pinene \\
6.401 & Camphene \\
6.817 & Sabinene \\
6.881 & 2-beta-pinen \\
7.079 & Beta-Myrcene \\
7.338 & I-Phellandrene \\
7.435 & Delta.3 Carene \\
7.544 & alfa-Humulene (CAS) \\
7.678 & Benzene, 1-methyl-3-(1-methylethyl)- \\
7.744 & dl-Limonene \\
8.242 & y-Terpinene \\
8.731 & Cyclohexene, 1-methyl-4-(methylethylidene)- \\
8.879 & Linalool L \\
12.492 & q-Elemen (CAS) \\
13.146 & Copaene \\
13.388 & Beta Elemenen \\
13.998 & Caryophyllene \\
14.277 & Guaia-1(5),11-diene \\
14.676 & Alfa-Humulene \\
15.426 & Beta-Seline (CAS) \\
15.630 &
\end{tabular}

b) Sumatera island

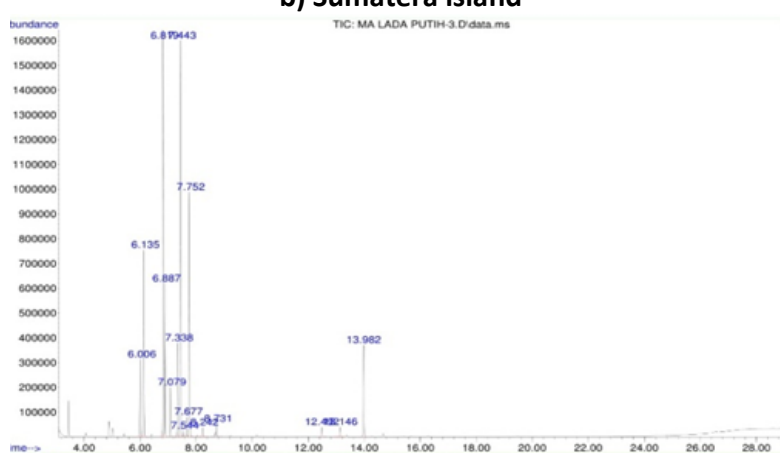

d) Java island

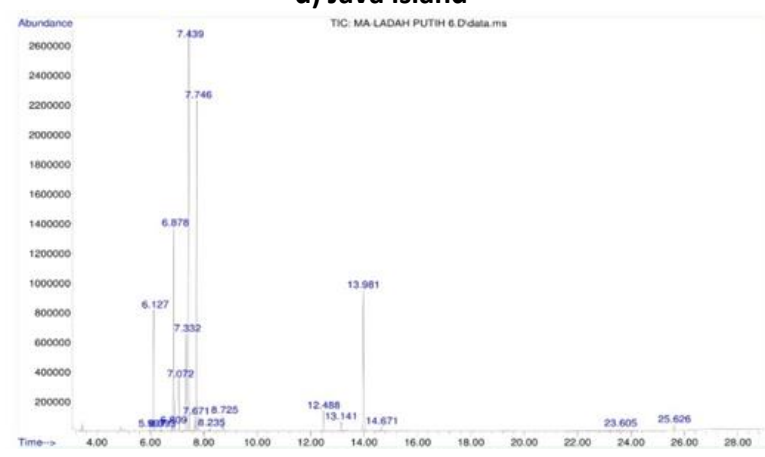

Figure 1: Chromatogram of white pepper's essential oils sample 
The spectrum of the six main molecules can be seen in Figure 2. The identity of each molecule was determined based on the value of the spectrum match factor (MF) of the tested molecules against the data library. Match factor data can be seen in Table III. MF values that are close to 999 or greater than 700, indicate that the molecular identities are very compatible (Reichenbach et al., 2019). The data library used was the NIST11. The

a)

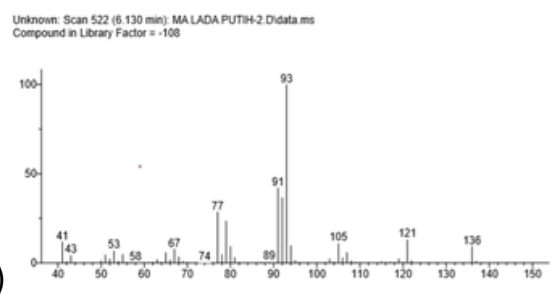

b)

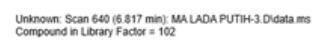

c)

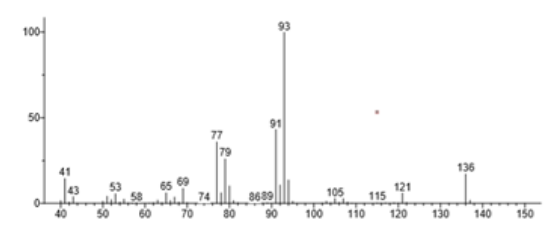

d)
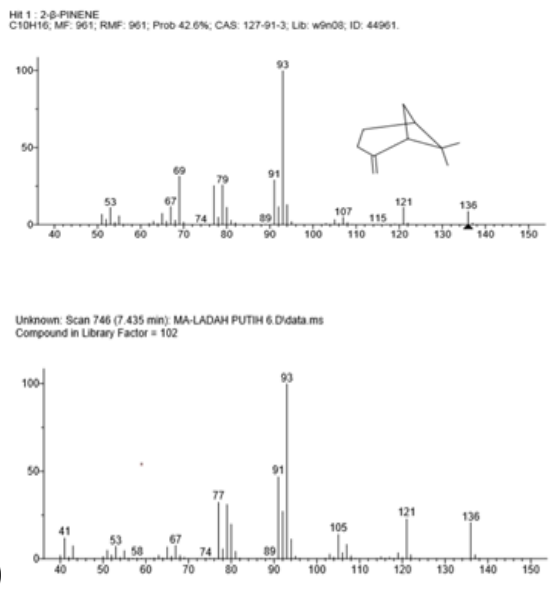

e)
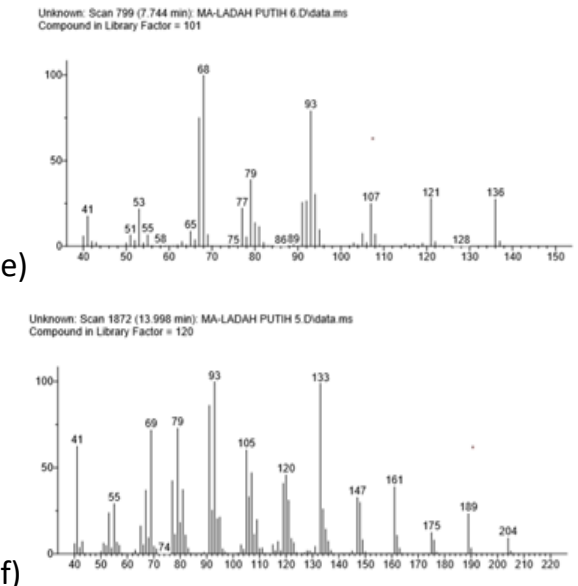

results were similar to those obtained by Liu in 2007. Liu, Song and $\mathrm{Hu}$ analysed the white pepper essential oil components using the GC-MS method without mentioning the location from which the pepper was obtained. They also showed that the main components of this pepper were caryophillene, 3-carene, $d$ limonene, beta-pinene, and alpha-pinene.
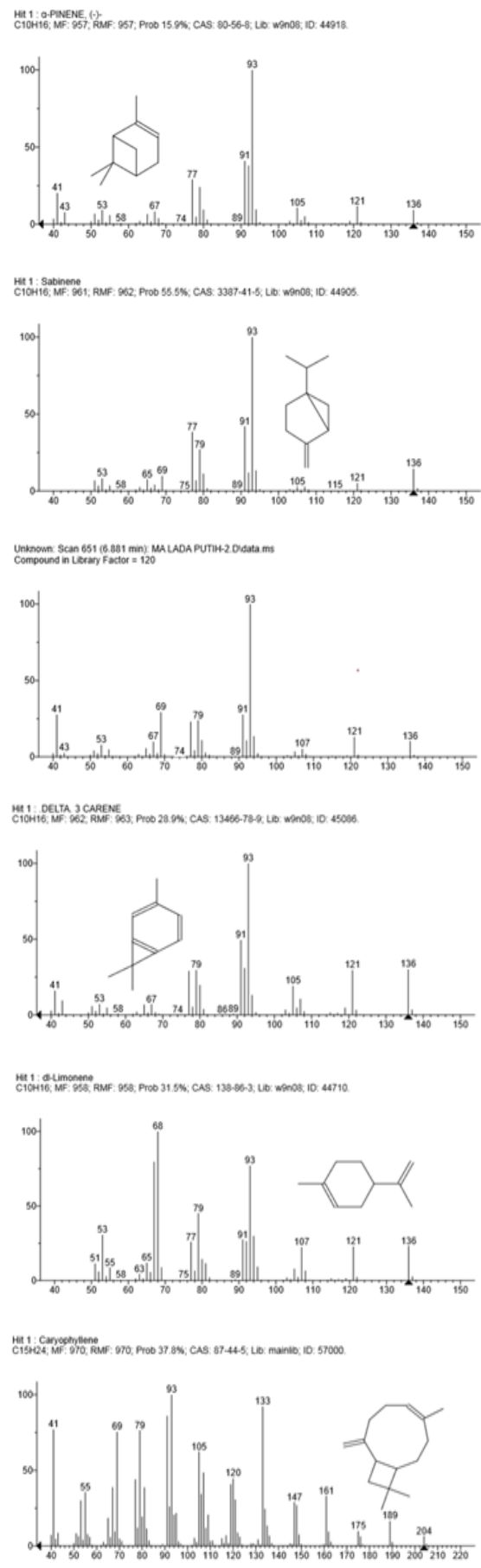

Figure 2: Spectrum of the six main molecules 
Table III. Match Factor (MF) values of main molecules in the white pepper samples

\begin{tabular}{|c|c|c|c|c|c|c|c|}
\hline No & Compound & Retention time & MF & $\begin{array}{l}\text { \%Area } \\
\text { Java }\end{array}$ & Sumatera & Kalimantan & Sulawesi \\
\hline 1 & $\alpha$-pinene & 6,130 & 957 & 7,83 & 9,92 & 10,65 & 5,20 \\
\hline 2 & Sabinene & 6,817 & 961 & 0,41 & 21,58 & 0,14 & 0,24 \\
\hline 3 & Beta-Pinene & 6,881 & 961 & 13,03 & 8,18 & 14,82 & 9,48 \\
\hline 4 & $\Delta$-3-carene & 7,435 & 962 & 27,83 & 21,39 & 24,98 & 21,37 \\
\hline 5 & dl-Limonene & 7,744 & 958 & 21,68 & 15,41 & 17,86 & 16,08 \\
\hline 6 & Caryophyllene & 13,998 & 970 & 13,18 & 6,99 & 11,68 & 30,90 \\
\hline
\end{tabular}

\section{Conclusion}

The white pepper essential oil from Java, Sumatra, and Kalimantan Islands contained 22 constituent compounds. In addition, those from different islands have specific compounds which relate to their differences in composition. Alfa-pinene, Sabinene, and caryophillene were dominantly found in white pepper from the Kalimantan, Sumatra, and Sulawesi Islands, respectively. Meanwhile, those from Java Island contained beta-pinene, delta-carene and caryophillene in similar quantities.

\section{References}

Calo, J. R., Crandall, P. G., O'Bryan, C. A., \& Ricke, S. C. (2015). Essential oils as antimicrobials in food systems - A review. In Food Control. https://doi.org/10.1016/j.foodcont.2014.12.040

Direktorat Jendral Perkebunan. (2019). Statistik perkebunan Indonesia 2017-2019 : Kopi. In Direktorat Jenderal Perkebunan Kementerian Pertanian.

Fokom, R., Adamou, S., Essono, D., Ngwasiri, D. P., Eke, P., Teugwa Mofor, C., Tchoumbougnang, F., Fekam, B. F., Amvam Zollo, P. H., Nwaga, D., \& Sharma, A. K. (2019). Growth, essential oil content, chemical composition and antioxidant properties of lemongrass as affected by harvest period and arbuscular mycorrhizal fungi in field conditions. Industrial Crops and Products. https://doi.org/10.1016/j.indcrop.2019.111477

Liu, L., Song, G., \& Hu, Y. (2007). GC-MS analysis of the essential oils of Piper nigrum L. and Piper longum L. Chromatographia. https://doi.org/10.1365/s10337-007-0408-2

Li, S., Lv, X., Cheng, K., Tian, Y., Huang, X., Kong, H., Duan, Y., Han, J., Liao, C., \& Xie, Z. (2019). Discovery of novel 2,3-dihydro-1Hinden-1-amine derivatives as selective monoamine oxidase $\mathrm{B}$ inhibitors. Bioorganic and Medicinal Chemistry Letters. https://doi.org/10.1016/j.bmcl.2019.02.030

Liu, Z., Kuang, S., Qing, M., Wang, D., \& Li, D. (2019). Metabolite profiles of essential oils and SSR molecular markers in Juniperus rigida Sieb. et Zucc. from different regions: A potential source of raw materials for the perfume and healthy products. Industrial Crops and Products. https://doi.org/10.1016/j.indcrop.2019.03.034
Moghaddam, M., \& Mehdizadeh, L. (2017). Chemistry of Essential Oils and Factors Influencing Their Constituents. In Soft Chemistry and Food Fermentation. https://doi.org/10.1016/b978-0-12-811412-4.00013-8

Reichenbach, S. E., Tao, Q., Cordero, C., \& Bicchi, C. (2019). A datachallenge case study of analyte detection and identification with comprehensive two-dimensional gas chromatography with mass spectrometry (GCXGC-MS). Separations, 6(3). https://doi.org/10.3390/separations6030038

Tamokou, J. de D., Mbaveng, A. T., \& Kuete, V. (2017). Antimicrobial Activities of African Medicinal Spices and Vegetables. In Medicinal Spices and Vegetables from Africa: Therapeutic Potential Against Metabolic, Inflammatory, Infectious and Systemic Diseases. https://doi.org/10.1016/B978-0-12809286-6.00008-X

Zhao, J., Davis, L. C., \& Verpoorte, R. (2005). Elicitor signal transduction leading to production of plant secondary metabolites. In Biotechnology Advances. https://doi.org/10.1016/j.biotechadv.2005.01.003 